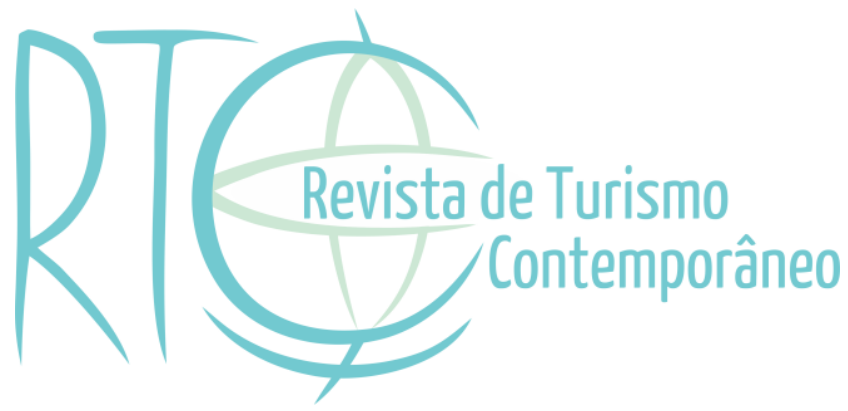

\title{
Alternativas ao desenvolvimento, autonomia dos povos indígenas e limitações: o caso do turismo em terras indígenas
}

Alternatives to development, autonomy of indigenous peoples and limitations: the case of tourism in indigenous lands

\section{Sandra Dalila Corbari}

Doutoranda em Meio Ambiente e Desenvolvimento (MADE) pela Universidade Federal do Paraná UFPR, Curitiba/PR, Brasil

E-mail: corbari91@hotmail.com

Artigo recebido em: 29-07-2017

Artigo aprovado em: 07-12-2017 


\section{RESUMO}

A humanidade vivencia uma crise ambiental resultante do modo como a natureza foi e vem sendo utilizada em prol do crescimento econômico. A preocupação com a má utilização dos recursos naturais e com o modo como o desenvolvimento era encarado ganhou força apenas após a Segunda Guerra Mundial. A partir desse período, uma série de convenções, informes e declarações buscaram traçar novos rumos ao desenvolvimento, o que ocorreu, principalmente, por meio do desenvolvimento sustentável. No entanto, modelos hegemônicos não contribuem para que as mais diversas sociedades possam promover suas alternativas ao desenvolvimento, como é o caso dos povos indígenas do Brasil. Esses povos vêm buscando sua autonomia na gestão de suas terras e de seus futuros. Dentre algumas comunidades indígenas evidencia-se a prática do turismo, que até o ano de 2015 não tinha regulamentação pelo governo federal. Desse modo, o presente ensaio teórico buscou discorrer sobre os entraves às comunidades no processo de regulamentação da atividade turística. Por meio de uma pesquisa bibliográfica e documental (legislação), compreendeu-se que o processo de regulamentação do turismo em Terras Indígenas (TIs) perdurou por décadas e mesmo sendo alcançada, é um processo burocrático, espelhado em modelos hegemônicos-capitalistas-ocidentais e que não possibilitam a prática autônoma dos povos indígenas.

Palavras-chave: Desenvolvimento Sustentável. Alternativas ao Desenvolvimento. Terras Indígenas. Turismo.

\section{ABSTRACT}

Humanity experiences an environmental crisis resulting from the way a nature has been and is being used for economic growth. Concern over the misuse of natural resources and the way in which development was viewed was strengthened only after World War II. Since that time, a series of conventions, reports and declarations sought new directions for development, which occurred mainly to the means of sustainable development. However, hegemonic models do not contribute so that the most diverse societies can promote their alternatives to development, as is the case of the indigenous peoples of Brazil. These peoples have been seeking their autonomy in the management of their lands and their futures. Among some indigenous communities there is evidence of a practice of tourism, which until 2015 was not regulated by the federal government. Thus, this theoretical essay aimed to discuss the obstacles placed to the communities in the process of regulation of the tourist activity. Through a bibliographical and documentary research, it is understood that the process of regulating tourism in indigenous lands lasted for decades, and even though it has been achieved, a bureaucratic process, mirrored in hegemonic-capitalist-Western models, which does not allow an autonomous practice of Indian people.

Keywords: Sustainable Development. Alternatives to Development. Indigenous Lands. Tourism. 


\section{INTRODUÇÃO}

A humanidade vivencia uma crise ambiental - um dos desdobramentos de uma crise global -, resultante do modo como a natureza foi utilizada ao longo do tempo em prol da manutenção do sistema econômico (Larrea, 2010), bem como da forma como diversas populações humanas encaram o crescimento econômico e o desenvolvimento.

Embora alguns estudiosos alertassem sobre a má utilização dos recursos naturais antes, foi apenas após a Segunda Guerra Mundial que a preocupação com esse fato ganhou força (Foladori, 2001). Nesse momento, a exaustão provocada pelo modelo Fordista de produção, promoveu várias tentativas de adaptação do modelo hegemônico de desenvolvimento - gerando diversos encontros políticos e divulgação de informes, embora essas tentativas tenham vindo, boa parte, dos países capitalistas, ditos desenvolvidos (Godoy, s/d; Foladori, $2001 \&$ Pierri, 2004).

Dada a (in)sustentabilidade das sociedades modernas, tornou-se imprescindível impulsionar novos modos de produção, consumo e organização da vida. Nesse sentido, emergiu uma variedade de novas perspectivas de desenvolvimento e novos modelos de economia. Os conceitos mais difundidos foram o ecodesenvolvimento (cunhado por Maurice Strong e disseminado por Ignacy Sachs) e desenvolvimento sustentável, termo que ganhou notoriedade e popularizou-se a partir de 1987, por conta da publicação do informe "Our Common Future” (Nosso Futuro Comum) (ONU, 1987). Outros conceitos que se apresentam é o desenvolvimento à escala humana e o desenvolvimento humano (Larrea, 2010; Max-Neef, 2012). No entanto, nenhum desses modelos alternativos de desenvolvimento questiona o capitalismo, apenas promovem o desenvolvimento humano sustentável na sociedade capitalista (Larrea, 2010). O que pode ser aplicado também ao conceito de ecodesenvolvimento. Cabe salientar que há outras perspectivas que se contrapõem ao modelo estabelecido de forma crítica, como a ecologia política, a ecossocioeconomia e o enfoque decolonial.

Tendo em vista esse debate, apresenta-se, de forma breve, o processo de busca pela autonomia dos povos indígenas brasileiro, à luz do direito. Ou seja, como os instrumentos legais vêm auxiliando na busca por um desenvolvimento alternativo, próprio de cada povo. Nesse sentido, o presente ensaio teórico explorou a regulamentação do turismo, enquanto alternativa econômica para os povos indígenas, bem como se propôs a discorrer sobre os entraves postos às comunidades no processo de regulamentação dessa atividade, tendo como 
base teórica a perspectiva do desenvolvimento, alternativas de desenvolvimento e a possibilidade de alternativas ao desenvolvimento.

O presente ensaio científico teórico foi elaborado utilizando-se de fontes bibliográfica e documental, sendo que essas últimas dizem respeito a instrumentos legais. A bibliografia utilizada decorre de leituras e discussões das quais a autora participou no Programa de Pós-graduação em Meio Ambiente e Desenvolvimento (MADE), na Universidade Federal do Paraná, mais especificamente no módulo denominado "Sociedade, Meio Ambiente e Desenvolvimento". Tais discussões giraram em torno dos conceitos de desenvolvimento, os desenvolvimentos alternativos (dentre os quais está englobado o desenvolvimento sustentável) e as alternativas ao desenvolvimento. Para esses tópicos, foram utilizados textos de autores que trazem a perspectiva do desenvolvimento (como Celso Furtado), suas alternativas (Ignacy Sachs \& Manfred Max-Neff), além de autores que discorrem sobre a pauta socioambiental (como Joan Martinez-Alier, Henri Acselrad, Clóvis Cavalcanti, Antônio Carlos Diegues, Guillermo Foladori e Enrique Leff). Tais estudiosos foram agregados ao debate a respeito do turismo, a fim de se traçar uma pesquisa de caráter interdisciplinar, dialogando com outras disciplinas para construir o conhecimento no campo do turismo.

A isso, acrescentou-se a temática do turismo em áreas indígenas, tema anteriormente estudado pela autora. Quanto a isso, no que se refere aos documentos legais a respeito do turismo em áreas indígenas, tem-se os principais marcos legais até a regulamentação: Constituição Federal de 1988, Decreto Federal no 5.051/2004, Decreto Federal no 7.747/2012 e a Instrução Normativa da Funai $n^{\circ}$ 03/2015. Além disso, materiais bibliográficos anteriormente conhecidos pela autora foram utilizados na argumentação. Buscou-se abordar desde um viés crítico os obstáculos enfrentados pelas comunidades indígenas brasileiras mediante projetos e modelos ocidentais-capitalistas-hegemônicos.

Desse modo, aborda-se a questão do desenvolvimento e, em seguida, o desenvolvimento sustentável e outras perspectivas. Após isso, apresenta-se brevemente a busca pela autonomia, autogestão e autogoverno dos povos indígenas e como a legislação vem respaldando esses ideais. Na sequência, apresenta-se o caso da regulamentação do turismo e seus entraves e, ao final, as considerações finais. 


\section{O DESENVOLVIMENTO E SUA PROBLEMÁTICA}

O conceito inicial de desenvolvimento surgiu a partir da obra de Rostow (1971 ${ }^{1}$ apud Layrargues, 1997), que, baseado no darwinismo social, defendeu a ideia de sucessão evolutiva de estágios, onde as sociedades humanas evoluiriam de um modelo de sociedade rudimentar ao modelo de civilização ocidental industrializada, de consumo (Layrargues, 1997). Destarte, Rostow (1971 apud Layrargues, 1997) ressaltava que as diferenças culturais não diziam respeito às variadas formas de apropriação e interação com o ambiente, mas à consequência dos retardamentos à modernização e, nesse sentido, a cultura que estaria no ápice evolutivo seria a dos Estados Unidos, enquanto as culturas presentes nos países periféricos seriam um entrave ao desenvolvimento e deveriam ser eliminadas ou superadas.

Consequentemente, o "jeito americano de viver" passou a ser visto como representação de uma sociedade desenvolvida para o resto do mundo e, com isso, os países do denominado "Terceiro Mundo", juntamente aos países que haviam sido recém-liberadas do colonialismo europeu, aceitaram a condição de países subdesenvolvidos (Layrargues, 1997).

Essa apropriação da natureza perpassa vários modelos econômicos adotados ao longo do tempo, podendo ser citado o pensamento mercantilista, embasado na acumulação de dinheiro ou metais preciosos, na especulação e no comércio como fonte de riquezas (Pierri, 1999), contribuindo para a expansão do uso do solo e recursos naturais em colônias recéminstauradas, como o Brasil. Esse processo do capital mercantil iria transformar os locais conquistados, séculos mais tarde, em regiões "subdesenvolvidas" da economia mundial (Leff, 2000). No entanto, foi apenas no Século XIX que a conscientização e estudos sobre os impactos do capitalismo nas sociedades e no meio ambiente começaram a tomar maior força. Isso se deu juntamente ao surgimento do conceito de ambientalismo, tendo suas raízes na crítica naturalista à destruição da natureza, em decorrência da Revolução Industrial, bem como na crítica social feita aos efeitos negativos da industrialização e colonização (Pierri, 2004).

Naquela época, os conservacionistas dos Estados Unidos estavam preocupavam com a perda de terras públicas e destruição de bosques nativos, o que os levou a reivindicar a preservação de espaços com ampla biodiversidade, afastando desses espaços a presença humana (Pierri, 2004). Esse movimento culminou na criação dos primeiros parques nacionais do mundo, como o Parque de Yellowstone, além de fortalecer diversas associações

\footnotetext{
${ }^{1}$ Rostow, W.W. (1971). Etapas do desenvolvimento econômico. Rio de Janeiro: Zahar.
} 
conservacionistas e inspirar a criação das primeiras leis em defesa da natureza, exemplo que posteriormente foi seguido por países europeus como a Inglaterra e a França, assim como destacado pela autora citada.

Embora alguns estudiosos já alertassem sobre a má utilização dos recursos naturais, foi apenas após a Segunda Guerra Mundial que a preocupação com o meio ambiente ganhou força (Foladori, 2001). Conforme ressaltado por Godoy (s/d), nas décadas de 1950 e 1960 ocorreram algumas mudanças nas relações estabelecidas no pós-guerra por conta da atuação dos sindicatos nos países ditos desenvolvidos e a reprodução do modelo produtivo "ideal" para os países que ainda não tinham alcançado o status de "desenvolvido". O estabelecimento de relações comerciais mais dinâmica, resultaram não apenas na exploração de recursos naturais e matérias-primas, mas, também, na busca pela modernização e industrialização por parte dos países subdesenvolvidos, inspirados no modelo Fordista de produção (Godoy, s/d).

Até o período citado acima os custos ambientais (uso intensivo dos recursos naturais e de degradação da natureza) não eram considerados apenas necessários no processo de desenvolvimento, mas também normais (Diegues, 1992). Já na década de 1970, se evidenciaram as consequências sociais, econômicas e ecológicas do modelo Fordista (Godoy, s/d), foi quando se introduziu a crise ambiental ${ }^{2}$ à cena politica global (Foladori, 2001; Pierri, 2004).

Em realidade, a crise ambiental é apenas uma das facetas de uma crise global. As inúmeras estratégias para se alcançar o suposto desenvolvimento gerou uma crise global de múltiplas dimensões (Larrea, 2010). Concomitantemente, houve a prospecção de uma série de informes científicos alarmista, como o informe "Limites do Crescimento" (The Limits to Growth), em 1972, encomendado pelo Clube de Roma ao Massachusetts Institute of Technology (MIT) e, em 1987, o relatório "Nosso Futuro Comum” (Our Common Future Relatório Brundtland). Tais relatórios tinham características catastrofistas, sob um denominador comum: os limites físicos do crescimento e proposta de crescimento populacional e econômico zero (Foladori, 2001 \& Pierri, 2004), tese defendida por Malthus. Também foram realizadas várias conferências para tratar do tema, como a Conferência de Founex, em 1971 e a Conferência de Estocolmo, em 1972.

\footnotetext{
${ }^{2}$ A crise ambiental foi respaudada por indicadores como devastação das matas, contaminação da água, costas e mares, sobreexploração de aquíferos, erosão de solos, desertificação, perda da diversidade agricola, destruição da camada de ozônio e aquecimento global (Foladori, 2001). No entanto, essa crise não se manisfeta apenas na destruição e degradação do meio físico e biológico. Junto ao processo de degradação ambiental, conjuga-se uma gama de impactos negativos nos âmbitos econômicos, sociais e culturais, afetando, em sua maioria, as populações pobres (Leff, 2000).
} 
Desse modo, faz-se necessário repensar o modelo hegemônico de desenvolvimento, que vem sendo emparelhado ao crescimento econômico. Nesse sentido, cabe destacar a diferença estrutural dos conceitos de crescimento e desenvolvimento. Enquanto o primeiro visa maximização da riqueza econômica sem escrúpulos, o segundo exige que se evite a competitividade autodestrutiva, com base na depreciação da força de trabalho e dos recursos naturais (Sachs, 2008). O crescimento é sinônimo de aumento ou expansão, representado pelo aumento quantitativo da escala física, enquanto o desenvolvimento é sinônimo de mudança, evolução e diz respeito a uma melhoria qualitativa ou florescimento de potencialidades, destarte, o desenvolvimento não implica crescimento material, mas pode inclui-lo (Cavalcanti, 2012. Ademais, como ressalta o ecodesenvolvimentista Ignacy Sachs (2008), o desenvolvimento econômico tem sido uma exceção histórica e não a regra, não ocorre naturalmente como consequência das forças de mercado, pois, esses são apenas uma das instituições que contribuem para o processo de desenvolvimento.

Sachs (2008) destaca que a ideia de desenvolvimento implica a expiação e reparação de desigualdades históricas, criando uma conexão capaz de preencher o abismo civilizatório as antigas nações e a periferia colonial, ou seja, entre a minoria abastada economicamente e modernizada e a maioria proletária e tida como "atrasada". Nesse sentido, o desenvolvimento se diferente do crescimento econômico, uma vez que vai além da mera multiplicação da riqueza material, essa é uma condição necessária, mas de forma alguma suficiente, para alcançar a meta de uma vida melhor, mais feliz e completa, assim como ressaltado pelo autor supracitado.

Não obstante, assim como destacado por Larrea (2010), o conceito de desenvolvimento entrou em uma crise profunda, não apenas pela perspectiva colonialista pela qual foi construído, mas também pelos resultados não tão eficientes, gerados no mundo inteiro. Admite-se que a conexão forte entre as questões ambientais e econômicas havia sido subestimada durante a fase inicial de constituição de entidades que remetiam à proteção do meio ambiente (Sachs, 2008). Ao se falar em desenvolvimento necessariamente se faz alusão a um modo de acumulação, a um sistema socioeconômico e político, a um tipo de relação social, entre outros aspectos (Larrea, 2010).

Assim como abordado por Guimarães e Fontoura (2012), se faz necessário reconhecer que a humanidade se aproxima - se é que já não sofre com os resultados - do esgotamento de um modelo de desenvolvimento não sustentável, ecologicamente depredador, socialmente perverso, politicamente injusto, eticamente reprovável e culturalmente alienado, 
produzindo diversos males no que se refere às questões ambientais e socioculturais. Seguindo esse pressuposto, faz-se mister a adoção de um modelo que vise a sustentabilidade.

Posto isso, frente às consequências devastadoras do neoliberalismo, surgiu a necessidade de orientar os estilos de desenvolvimento, criando novos paradigmas, como é o caso do desenvolvimento sustentável, desenvolvimento à escala humana, desenvolvimento humano, entre outros (Leff, 2000; Larrea, 2010).

\section{O DESENVOLVIMENTO SUSTENTÁVEL E OUTRAS PERSPECTIVAS}

Dada a (in)sustentabilidade das sociedades modernas tornou-se imprescindível impulsionar novos modos de produção, consumo e organização da vida. Nesse sentido, emergiu uma variedade de novas perspectivas de desenvolvimento e novos modelos de economia.

Enquanto a economia convencional ${ }^{3}$ exclui do processo econômico a natureza, outras concepções buscam internalizá-la, como é o caso da economia ambiental, que procura precificar a natureza, e a economia ecológica, a qual atribui à natureza o papel de suporte insubstituível para a sociedade (Cavalcanti, 2015). Entre as correntes não tradicionais, tem-se a economia verde, a qual Martínez-Alier (2007) nomeia "evangelho da ecoeficiência", um tipo de ecologismo de resultados que se preocupa com a economia na sua totalidade e, por vezes, defende o crescimento econômico ainda que não a qualquer custo, acreditando no "desenvolvimento sustentável", na "modernização ecológica" e o uso adequado dos recursos. Além dessa corrente do ambientalismo, o autor supracitado cita o "culto ao silvestre", que é o caso da ecologia profunda, respaldada pela biologia da conservação, para a qual a natureza possui valor sagrado; e o "ecologismo dos pobres", na perspectiva da ecologia política, relacionado aos interesses nos recursos e serviços ambientais, indispensáveis à vida humana, levantando a discussão a respeito dos danos ambientais de forma desigual, atingindo, na maioria das vezes, as populações pobres, assinalando que, desgraçadamente, o crescimento econômico implica maiores impactos no meio ambiente. Sua aplicação vem crescendo mundialmente por conta dos conflitos ecológicos distributivos, ou seja, aqueles conflitos que, na visão de Zhouri e Laschefski (2010), indicam graves desigualdades sociais em torno do acesso e utilização dos recursos naturais.

\footnotetext{
${ }^{3}$ Pode-se englobar os economistas neoclássicos, keynesianos, marxistas, institucionalistas, estruturalistas, monetaristas, economistas políticos, entre outros (Cavalcanti, 2015).
} 
No entanto, as alternativas teóricas mais conhecidas são o ecodesenvolvimento e o desenvolvimento sustentável. O primeiro, proposto por Maurice Strong e apresentado por Ignacy Sachs, é um modelo de desenvolvimento adaptado às regiões rurais do que se denomina Terceiro Mundo, propondo a conservação da estrutura produtiva dos recursos renováveis, utilizando tecnologias apropriadas e pautado na educação libertadora como promovedora do conhecimento necessário para o manejo ecologicamente correto dos recursos naturais (Pierri, 2001). Essa concepção incorporou parte das críticas ao conceito de desenvolvimento como equivalente a crescimento econômico, no entanto, assim como ressaltado pela autora citada, o ecodesenvolvimento não atraiu forças necessárias para convencer da urgência e visibilidade da proposta, além disso, a proposta não busca superar o capitalismo, mas sim introduzir critérios ecológicos ao funcionamento do mercado, tornandoo mais civilizado. Esse conceito foi facilmente substituído pelo de desenvolvimento sustentável, entendidos como sinônimos por vários pesquisadores e organizações.

Embora a consciência ambiental viesse se expandindo desde o encontro em Estocolmo, em 1972 (Leff, 2000), o termo desenvolvimento sustentável começou a ser usado a partir do Relatório Brundtland, em 1987 (ONU, 1987) e pode ser entendido como aquele que responde às necessidades do presente de forma igualitária, mas sem comprometer as possibilidades de sobrevivência e prosperidade das gerações futuras, e se estabelece que a pobreza, a desigualdade e a degradação ambiental podem ser analisadas de maneira isolada (Foladori, 2001). Segundo o informe, o desenvolvimento sustentável é um processo de mudança para um status harmônico para atender as necessidades e aspirações humanas (ONU, 1987), tal mudança deve considerar o produzir diferente, o consumir diferente e o se organizar diferente (Larrea, 2010).

No entanto, foi apenas na Conferência das Nações Unidas sobre o Meio Ambiente e Desenvolvimento, também conhecida como ECO-92, celebrada em 1992, no Rio de Janeiro, que o discurso de desenvolvimento sustentável foi legitimado, oficializado e amplamente difundido (Leff, 2000). Esse modelo de desenvolvimento sustentável se baseia em três diretrizes básicas: ser ecologicamente harmônico, economicamente eficiente e socialmente justo (Larrea, 2010).

Sachs (2008) ressalta que para o desenvolvimento, ao invés de maximizar o crescimento do Produto Interno Bruto (PIB), tem como objetivo principal a promoção da igualdade e equiparação econômica de forma a reduzir a pobreza. A esse foco social, o desenvolvimento sustentável acrescenta outra dimensão: a sustentabilidade ambiental, assim 
como ressaltado pelo autor. Sendo assim, os cinco pilares desse modelo são, segundo o estudioso supracitado: a) Social, que tem relação à perspectiva de disrupção social em vários locais do planeta; b) Ambiental, em suas dimensões de provisão de recursos e recipiente de resíduos; c) Territorial, que diz respeito à distribuição espacial das populações, recursos naturais e atividades; d) Econômico, tendo em vista que a viabilidade econômica é essencial para que as coisas aconteçam; e) Político, considerando o valor fundamento da governança democrática (Sachs, 2008).

Não obstante, o discurso da sustentabilidade e do desenvolvimento sustentável foi facilmente apropriado pelo capital, que, passa de formas tradicionais, selvagens e violentas de apropriação dos recursos, de mecanismos econômicos, de trocas desiguais de matérias-primas, para uma estratégia discursiva legitimadora dessa apropriação (Leff, 2000), além disso, esses termos são amplamente utilizados nos discursos governamentais e preâmbulos de projetos de investimentos financiados por instituições financeiras (Diegues, 1992). Em torno da sustentabilidade há uma luta entre os que buscam alterar ou reforçar a distribuição de poder sobre os mercados e mecanismos de acesso aos recursos, os quais se apresentam como detentores da nova eficiência ampliada, ou seja, da utilização "sustentável” dos recursos, caracterizando assim a ambientalização dos discursos dos diversos atores envolvidos (Acselrad, 2004; 2010).

Leff (2000) enaltece que há uma operação simbólica que redefine a biodiversidade como patrimônio comum da humanidade, enquanto as populações dos países periféricos são categorizadas como capital humano do planeta. Nesse sentido, o discurso não procura internalizar as condições ecológicas da produção, mas sim proclamar o crescimento econômico como sustentável, assim como afirma o autor citado anteriormente. O desenvolvimento sustentável assume a postura de um projeto ecológico do neoliberalismo, produzindo a ilusão de que se vive uma mudança de paradigma, de caráter gradual e que desembocará na sustentabilidade socioambiental (Layrargues, 1997).

$\mathrm{O}$ autor citado destaca que, enquanto o ecodesenvolvimento reforça o perigo da crença ilimitada na tecnologia moderna, privilegiando a criação e uso de tecnologias endógenas, o desenvolvimento sustentável continua postulando que a tecnologia moderna tem forte potencial, propondo a transferência dessa tecnologia, dos países ricos, como critério de “ajuda" aos países pobres. Além disso, esse autor adiciona que, o ecodesenvolvimento propõe limites à atuação do mercado, enquanto o desenvolvimento sustentável afirma que a instalação do mercado total na economia é a solução para a crise ambiental. 
Já outras concepções, como o desenvolvimento à escala humana e o desenvolvimento humano, partem do princípio de que o desenvolvimento deve ter como centro o ser humano e não o mercado ou a produção, assim como não se deve medir o Produto Interno Bruto (PIB), e sim o nível de satisfação das necessidades humanas (Larrea, 2010). O desenvolvimento à escala humana privilegia o ser humano, possibilitando o desabrochar de suas potencialidades, assegurando-lhes o suprimento de suas carências básicas e as condições para uma vida digna (Max-Neef, 2012).

Larrea (2010) destaca que nem o desenvolvimento sustentável, nem o desenvolvimento à escala humana e o desenvolvimento humano, questionam o capitalismo, apenas promovem o desenvolvimento humano sustentável dentro da sociedade capitalista - o que poderia ser aplicado também ao conceito de ecodesenvolvimento. Ademais, a pesquisadora citada ressalta que esses modelos alternativos de desenvolvimento não se enquadram em todas as sociedades, sendo necessário averiguar qual o melhor método e ferramenta para a transformação, ou seja, não é possível aplicar um modelo homogêneo em sociedades que diferem entre si.

Nesse sentido, cabe destacar que a capitalização da natureza vem gerando manifestações de resistência, articulando-se na construção de outros paradigmas de sustentabilidade (Larrea, 2010), como é o caso da ecossocioeconomia, que enfatiza o enfoque metodológico-empírico, visando problemas e soluções reais e palpáveis e é utilizada para denominar experiências em curso (Sampaio, Azkarraga \& Altuna, 2009). Trata-se de uma teoria construída a partir de experimentações e da complexidade cotidiana (Sampaio, 2009).

Contudo, para Diegues (1992), há a necessidade de se pensar em sociedades sustentáveis, ao invés de desenvolvimento sustentável. Esse autor defende que as sociedades devem estar ancoradas em modos particulares, históricos e culturais de relações com vários ecossistemas existentes e dos seres humanos entre si. Nesse aspecto, mais recentemente, viuse emergir paradigmas de grande importância, desde uma perspectiva decolonial, novas perspectivas epistemológicas do Sul, dos povos originários, as lutas emancipadoras e as teorias críticas. Um exemplo disso é o "buen vivir", aplicado à Constituição do Equador, externalizado pela expressão na língua quéchua "Sumak Kawsay" (Larrea, 2010), apenas para citar. Cabe citar Furtado (2002), que tinha como uma de suas questões centrais a possibilidade, em meio a processos de desenvolvimento, dos povos preservarem suas identidades culturais e nacionais. Entende-se que o meio para que essa preservação aconteça é a busca por um modelo econômico que esteja alinhado ao modo de vida e à ética local. 


\section{A BUSCA PELA AUTONOMIA E AUTODETERMINAÇÃO DOS POVOS INDÍGENAS À LUZ DO DIREITO}

Para iniciar o presente tópico faz-se necessário recorrer à legislação brasileira, mais especificamente a alguns instrumentos legais. O primeiro a ser citado, e que fortaleceu os direitos básicos dos povos indígenas no Brasil, é a Constituição Federal de 1988, que tem um capítulo exclusivo tratando dos direitos desses povos - "Capítulo VIII - dos índios" (Constituição Federal, 1988). Foi a partir desse momento histórico que o direito coletivo culturalmente diferenciado das populações indígenas passou a ser mais recorrente na legislação brasileira.

É possível verificar que o art. 231 determina que "são reconhecidos aos índios sua organização social, costumes, línguas, crenças e tradições [...]” (Constituição Federal, 1988, $\mathrm{s} / \mathrm{p}$ ). Isso demonstra que esses povos têm o direito de manter sua cultura e sua organização social como acreditarem ser o adequado, preservando seu modo de vida ou alterando conforme necessidade ou ocasião. Além disso, o $§ 1^{\circ}$ desse artigo explica que

\footnotetext{
São terras tradicionalmente ocupadas pelos índios as por eles habitadas em caráter permanente, as utilizadas para suas atividades produtivas, as imprescindíveis à preservação dos recursos ambientais necessários a seu bem-estar e as necessárias à sua reprodução física e cultural, segundo seus usos, costumes e tradições (Constituição Federal, 1988, s/p).
}

Ou seja, tem-se a necessidade da autonomia para que as Terras Indígenas (TIs) sejam geridas conforme interesse e culturas, nos âmbitos sociais, culturais, políticas ou ambientais.

No que tange à autonomia e livre escolha do processo de desenvolvimento, o avanço sobre esse tema ocorreu após a promulgação da Convenção $\mathrm{n}^{\circ} 169$ da Organização Internacional do Trabalho (OIT) sobre Povos Indígenas e Tribais, de 1989, que se deu, no Brasil, por meio do Decreto ${ }^{\circ} 5.051$, de 19 de abril de 2004 (Decreto ${ }^{\circ}$ 5.051, 2004). Uma das bases desse documento foi o reconhecimento das "aspirações desses povos a assumir o controle de suas próprias instituições e formas de vida e seu desenvolvimento econômico, e manter e fortalecer suas identidades, línguas e religiões, dentro do âmbito dos estados onde moram" (Decreto $\left.\mathrm{n}^{\circ} 5.051,2004, \mathrm{~s} / \mathrm{p}\right)$.

O documento informa que os governos deverão adotar ações que, dentre outras medidas, "ajudem os membros dos povos interessados a eliminar as diferenças socioeconômicas que possam existir entre os membros indígenas e os demais membros da comunidade nacional, de maneira compatível com suas aspirações e formas de vida" (Decreto $\mathrm{n}^{\mathrm{o}}$ 5.051, 2004, s/p). Ou seja, a questão da escolha de como eliminar as diferenças 
socioeconômicas deve partir das comunidades interessadas e não de um modelo préestabelecido e hegemônico, como é o caso dos modelos citados no tópico anterior.

$\mathrm{O}$ art. $7^{\circ}$ dessa Convenção informa que

Os povos interessados deverão ter o direito de escolher suas próprias prioridades no que diz respeito ao processo de desenvolvimento, na medida em que ele afete as suas vidas, crenças, instituições e bem-estar espiritual, bem como as terras que ocupam ou utilizam de alguma forma, e de controlar, na medida do possível, o seu próprio desenvolvimento econômico, social e cultural. Além disso, esses povos deverão participar da formulação, aplicação e avaliação dos planos e programas de desenvolvimento nacional e regional suscetíveis de afetá-los diretamente (Decreto $\mathrm{n}^{\mathrm{o}}$ $5.051,2004, \mathrm{~s} / \mathrm{p})$.

Ademais, os planos de desenvolvimento econômico das regiões onde habitem comunidades indígenas devem priorizar a melhoria das condições de vida e trabalho e o nível de educação e saúde desses povos (Decreto $\left.n^{\circ} 5.051,2004\right)$. Um dos pontos essencial do documento é sobre o direito à terra e, mais do que isso, a salvaguarda das mesmas, por conta da relação dos povos indígenas com seus territórios, a importância não econômica, mas sim, cultural e espiritual.

No que se refere à economia, o art. 23 destaca que

o artesanato, as indústrias rurais e comunitárias e as atividades tradicionais e relacionadas com a economia de subsistência dos povos interessados, tais como a caça, a pesca com armadilhas e a colheita, deverão ser reconhecidas como fatores importantes da manutenção de sua cultura e da sua autossuficiência e desenvolvimento econômico [...] (Decreto $\mathrm{n}^{\circ}$ 5.051, 2004, s/p).

Ou seja, devem ser incentivadas, quando houver interesse das comunidades, atividades que gerem benefícios econômicos, de preferência que sejam concernentes ao modo de vida e cultura própria. $\mathrm{O}$ mesmo artigo menciona a necessidade de assistência técnica e financeira para que se possa alcançar o "desenvolvimento sustentado e equitativo".

Como um dos desdobramentos da Convenção nº169 da OIT tem-se, no Brasil, a instituição da Política Nacional de Gestão Territorial e Ambiental de Terras Indígenas (PNGATI), que se deu através do Decreto $\mathrm{n}^{\circ}$ 7.747, de 5 de junho de 2012 (Decreto $\mathrm{n}^{\circ}$ 7.747, 2012).

A PNGATI tem entre seus objetivos a proteção, a recuperação, a conservação e o uso sustentável dos recursos naturais em área indígenas, aliadas aos meios necessários para a melhoria da qualidade de vida, respeitando a autonomia sociocultural (Decreto $\mathrm{n}^{\mathbf{0}} 7.747$, 2012). Isso deve ser estabelecido por meio de diretrizes, dentre as quais se destaca o "[...] protagonismo e autonomia sociocultural dos povos indígenas, inclusive pelo fortalecimento de suas organizações [...]" (Decreto $\left.\mathrm{n}^{\mathrm{o}} 7.747,2012, \mathrm{~s} / \mathrm{p}\right)$. 
Os objetivos específicos dessa política são estabelecidos em eixos temáticos, dentre os quais se destaca nesse artigo o eixo 5, que diz respeito ao uso sustentável de recursos naturais e iniciativas produtivas indígenas. Entre os objetivos específicos desse eixo, destacase:

[...] b) fortalecer e promover as iniciativas produtivas indígenas, com o apoio à utilização e ao desenvolvimento de novas tecnologias sustentáveis; c) promover e apoiar a conservação e o uso sustentável dos recursos naturais usados na cultura indígena, inclusive no artesanato para fins comerciais; d) apoiar a substituição de atividades produtivas não sustentáveis em Terras Indígenas por atividades sustentáveis; [...] g) apoiar iniciativas indígenas sustentáveis de etnoturismo e de ecoturismo, respeitada a decisão da comunidade e a diversidade dos povos indígenas [...] h) promover a sustentabilidade ambiental das iniciativas indígenas de criação de animais de médio e grande porte; i) promover a regulamentação da certificação dos produtos provenientes dos povos e comunidades indígenas, com identificação da procedência étnica e territorial e da condição de produto orgânico, em conformidade com a legislação ambiental [...] (Decreto n ${ }^{\circ}$ 7.747, 2012, s/p).

Por meio desses objetivos, percebe-se que há uma busca pela implementação de atividades de cunho econômico, tendo em vista a autonomia e direito à decisão sobre seus próprios futuros, estabelecidos como prioridade pela OIT, e consequentemente a facilitação da busca por outro desenvolvimento.

Salienta-se, no entanto, que o Estado resiste ou, por vezes, se recusa a reconhecer os direitos coletivos dos povos indígenas, alegando que os direitos indígenas são de natureza individual, não admitindo incluir direitos como a autodeterminação, a autonomia, o autogoverno e o direito consuetudinário, justificando que esses são próprios aos Estados (Oliveira, 2008). Ademais, por vezes, os modelos alternativos ao desenvolvimento geram conflitos, dentre eles os ambientais, como aponta Acselrad (2004, p. 18) "os conflitos ambientais podem ser entendidos como expressão de tensões no processo de reprodução dos modelos de desenvolvimento", sendo recorrentes os conflitos envolvendo comunidades indígenas. Nesse sentido, a aplicação desses conceitos se torna ainda mais difícil, embora possam ser amplamente citadas as tentativas de autonomia, pelo menos econômica.

\section{A REGULAMENTAÇÃO DO TURISMO EM TERRA INDÍGENAS E SEUS ENTRAVES}

Dentre as iniciativas que buscam a autonomia indígena, algumas são relacionadas à atividade turística. No entanto, o turismo em TIs foi regulamentado apenas no ano de 2015, após décadas de debate entre entidades governamentais, estudiosos e comunidades indígenas. Brandão (2012) acreditava que o que impedia, até então, a criação de uma política específica 
para o tema era a ausência de sensibilidade dos gestores e planejadores das políticas públicas de turismo. Considera-se essa, no entanto, uma ideia equivocada, uma vez que o Ministério do Turismo (MTur) é apresentado como o único órgão responsável por essa política, não considerando que outros órgãos se fazem importantes, como a Fundação Nacional do Índio (Funai) e as próprias associações indígenas. Incluindo nisso a própria estratégia governamental de manutenção de certa tutela e vínculo de dependência dos povos indígenas.

Assim como o ressaltado acima, após anos de debate a Funai regulamentou, no dia 11 de junho de 2015, a atividade turística em TIs, mais especificamente o turismo de base comunitária e sustentável, por meio dos segmentos de etnoturismo e ecoturismo (Instrução Normativa $\left.n^{\circ} 03,2015\right)$. Abaixo apresenta-se uma tabela com a conceituação.

Tabela 1 - Conceituação de turismo de base comunitária, etnoturismo e ecoturismo.

\begin{tabular}{|c|c|}
\hline TIPO/SEGMENTO TURÍSTICO & CONCEITO \\
\hline Turismo de base comunitária & $\begin{array}{l}\text { O turismo de base comunitária tem como motivação a superação da } \\
\text { lógica capitalista utilitarista materialista, tendo por base os princípios } \\
\text { de equidade social, prudência ecológica e responsabilidade econômica } \\
\text { (Fortunato \& Silva, 2013), ou seja, ele não representa um segmento do } \\
\text { turismo, mas sim uma alternativa ao turismo convencional. O turismo } \\
\text { de base comunitária pode ser considerado um instrumento para inclusão } \\
\text { social e promoção do desenvolvimento sustentável, com plena } \\
\text { participação da população no processo de construção, planejamento e } \\
\text { organização da atividade turística (Brandão, 2012). }\end{array}$ \\
\hline Etnoturismo/Turismo étnico & $\begin{array}{l}\text { Inserido no turismo cultural, o turismo étnico sobrepõe-se em um } \\
\text { sistema preexistente de relações étnicas entre um grupo dominante e } \\
\text { um ou mais grupos marginalizados cujo atrativo turístico é o exotismo } \\
\text { de determinado grupo étnico, como, no caso do Brasil, os quilombolas, } \\
\text { as comunidades que representam os processos de imigração europeia e } \\
\text { asiática e outros grupos que preservam seu legado histórico-cultural e o } \\
\text { saber-fazer (Corbari, Bahl \& Souza, 2016a; Corbari; Bahl \& Souza, } \\
\text { 2016b). }\end{array}$ \\
\hline Ecoturismo & $\begin{array}{l}\text { O ecoturismo é uma convergência do turismo de natureza com o } \\
\text { turismo cultural e tem um caráter comunitário pautado no planejamento } \\
\text { participativo. Esse segmento não deve ser confundido com o turismo } \\
\text { ecológico ou com quaisquer atividades turísticas que sejam pautadas no } \\
\text { patrimônio natural como atrativo principal, pois aquele é uma junção } \\
\text { do ambiente natural e motivações culturais (Faria, 2008), embora } \\
\text { prevaleça o interesse, por parte do ecoturista, pelo ambiente natural. }\end{array}$ \\
\hline
\end{tabular}

Fonte: A autora (2017).

Conforme disposto, a Instrução Normativa 03 de 2015 considera o disposto no Decreto $n^{\circ} 5.051 / 2004$, no Decreto $n^{\circ} 7.747 / 2012$ e na Lei $n^{\circ} 12.593 / 2012$, anteriormente abordados. Além da regulamentação da atividade em si, estabelece normas e diretrizes relativas à atividade turística nas TIs (BRASIL, 2015). Segundo esse documento legal, são objetivos da visitação turística em TIs: 
[...] a valorização e a promoção da sociodiversidade e da biodiversidade, por meio da interação com os povos indígenas, suas culturas materiais, imateriais e o meio ambiente, visando à geração de renda, respeitando-se a privacidade e a intimidade dos indivíduos, das famílias e dos povos indígenas, nos termos por eles estabelecidos (Instrução Normativa $\mathrm{n}^{\circ}$ 03, 2015).

Assim, entende-se que a regulamentação ocorreu mediante entendimento de que o turismo seria um importante meio de obtenção de renda para as comunidades indígenas, ao mesmo tempo, se constituiria uma ferramenta para fortalecimento da etnicidade e divulgação das culturas indígenas. Desse modo, estaria regulamentada mais uma opção de atividade para os povos indígenas. No entanto, além do fato de ser necessária a autorização para execução de atividades relativas ao turismo, a regulamentação vem acompanhada de um processo burocrático e que não é concernente ao modelo de gestão próprio dos povos indígenas.

Para que as atividades turísticas ocorram em consonância com a lei faz-se necessário a elaboração de um Plano de Visitação, que deverá ser analisado pela Funai (Instrução Normativa $\left.\mathrm{n}^{\circ} 03,2015\right)$. Ou seja, é possível que a comunidade não tenha autorização para desenvolver o turismo. Além disso, é preciso enviar à Funai, periodicamente, relatórios sobre as visitações (Instrução Normativa $n^{\circ} 03,2015$ ). Isso demonstra que apesar do intuito desse órgão de estimular a autonomia dos povos indígenas no Brasil, ainda há controle do Estado sobre as decisões e atividades realizadas nas TIs. Ademais, ignora-se o sistema de gestão e as próprias peculiaridades das comunidades indígenas, diversas delas sem acesso a computadores ou internet e que, em boa parte, não contam com pessoas capacitadas para elaboração de tal documento.

Conforme o art. $5^{\circ}$ da Instrução Normativa, o Plano de Visitação precisa contemplar: objetivos e justificativa da proposta de visitação; público alvo, frequência de visitas previstas, quantidade máxima de pessoas por visita e previsão de duração das visitas; distribuição das competências, considerando os aspectos sociais, geracionais e de gênero; parceiros envolvidos no projeto, bem como suas responsabilidades e atribuições; descrição das atividades propostas ao visitante; delimitação do roteiro, constando mapa ou croqui; condições de transporte, hospedagem, alimentação e atividades correlatas à visitação; plano de negócios simplificado, contendo custos previstos para operação, manutenção e monitoramento da visitação e atividades, bem como previsão de receita, lucro e investimento; estratégia de atendimento de primeiros socorros; manual de conduta e boas práticas para visitantes e para a comunidade; estratégia de impedimento da entrada de bebidas e drogas nas comunidades indígenas e outros produtos ilícitos; estratégia de gestão de resíduos sólidos; estratégia de monitoramento da 
atividade de visitação; e estratégia de capacitação dos proponentes (Instrução Normativa $\mathrm{n}^{\circ}$ 03, 2015).

Embora diversas iniciativas - entre elas as de turismo - tenham o intuito de promover certa "liberdade de desenvolvimento" para os povos indígenas, elas ainda estão enraizadas no sistema capitalista e burocrático, como pode ser percebido nos parágrafos anteriores. Um exemplo disso ocorre com o povo Baniwa, como relatado por Luciano (2008): entre os Baniwa é crime não respeitar as decisões coletivas comandadas por chefes de clãs, sibs ou fratrias. Sendo assim, qualquer distribuição de bens ou serviços deveria obedecer à rede social e política estabelecida. No entanto, conforme esse autor, os procedimentos burocráticos dos projetos a ignoram, gerando conflitos sociais dentro do grupo, inclusive com ameaças ou mortes de lideranças jovens que não possuem o mesmo status que as autoridades tradicionais (chefes).

Cabe destacar, que modelos hegemônicos não permitem as diferentes formas culturais de apropriação do mundo material, das quais, consequentemente, emergiriam novos modelos de desenvolvimento (Acselrad, 2004) ou as denominadas modernidades alternativas (Zhouri \& Laschefski, 2010). Desse modo, assim como ressaltado por Zhouri e Laschefski (2010), a sustentabilidade das práticas de reprodução material e simbólica de diferentes populações, incluindo as indígenas, se veem ameaçadas.

Outra questão abordada por Luciano (2008) é que conceitos como etnodesenvolvimento e desenvolvimento sustentável, são limitados e não dão conta das realidades locais e específicas de cada grupo indígena. Assim, os legítimos projetos coletivos sociais desses povos e os próprios povos, ficam marginalizados, por não se enquadrarem no sistema político, cultural, econômico monolítico hegemônico. Concordar com essa lógica, pode ter um custo social e cultural, sobre o qual os povos indígenas precisam ter domínio.

Apesar de serem críticos ao modelo de desenvolvimento - e de vida - aplicado pela sociedade não indígena e terem consciência de que se faz necessário a atuação em prol de autonomia nas decisões sobre seu próprio futuro, bem como o direito à livre determinação, os indígenas não se permitem aplicar projetos adequados a seus modos de vida, principalmente porque ainda não alcançaram a autodeterminação e autonomia desejada. Desse modo, adéquam suas necessidades e anseios aos modelos de projetos oriundos da sociedade "brancacapitalista-desenvolvimentista-colonialista".

Nesse sentido, entende-se que ainda que o turismo tenha sido regulamentado nas TIs, o fato de que os projetos precisem passar pelo crivo da Funai e poderão, assim, não serem 
autorizados, poderia acarretar iniciativas sem aval do Estado, como já ocorria antes da publicação da Instrução Normativa. Com isso, a possibilidade de um "outro desenvolvimento" ou, até mesmo, alternativas dentro do desenvolvimento fica comprometida, uma vez que a autonomia, autogoverno e autogestão dos povos indígenas ainda não foram alcançados. Ademais os projetos estão carregados de burocracia e entraves. Por fim, acrescenta-se ainda que a regulamentação se restringe às TIs, ou seja, as porções de terra regularizadas pelo Estado, deixando de lado diversas aldeias que ainda não estão homologadas, ficando incerta a permissão de desenvolvimento de atividades turísticas nesses espaços.

\section{CONSIDERAÇÕES FINAIS}

Ao longo do tempo, as teorias econômicas foram adaptando seus discursos a respeito da utilização da natureza para geração de capital, discursos esses que estiveram, por um bom tempo, emparelhados ao discurso do desenvolvimento. Isso ocorreu, como pôde ser visto no presente artigo, pela própria essência do conceito, como uma sucessão evolutiva de estágios, onde o ápice seria o modelo de civilização ocidental industrializada, de consumo. Isso gerou um sentimento de inferioridade pelos países do "Terceiro Mundo" que aceitaram sua condição de subdesenvolvidos, buscando estratégias para "evoluir", utilizando-se dos modelos dos países ditos desenvolvidos. Essa busca por um desenvolvimento homogêneo (entendido sinônimo de crescimento econômico) gerou diversos problemas sociais, culturais e ambientais, desde escalas maiores como países, até escalas menores, como comunidades.

Com o entendimento e consenso a respeito de uma crise ambiental que despontava, deu-se início uma série de intentos para mudar a situação, tanto nos países industrializados, desenvolvidos, quanto nos subdesenvolvidos. Dentre esses intentos, verifica-se a realização de várias conferências; a publicação de informe; a promulgação de declarações, entre outros. Percebe-se que, por conta da preocupação com o modelo econômico hegemônico e a decorrente crise global, foram surgindo também conceitos e modelos de alternativas ao desenvolvimento, iniciando com o ecodesenvolvimento e seu sucessor, o desenvolvimento sustentável, fortemente em voga nos dias atuais, e perpassando por outros modelos, como a ecossocioeconomia.

Foi possível compreender que, embora vários modelos tenham surgido e, possivelmente, vários outros ainda surgirão, o discurso da sustentabilidade foi apropriado pelo capital. Além disso, os modelos nem sempre consideram as particularidades geográficas e 
culturais, buscando um modelo homogeneizante que possa ser aplicado em qualquer parte do globo terrestre. Nesse aspecto, se negligencia o papel das comunidades tradicionais e indígenas no processo, que poderia se denominar "reestruturação da relação ser humano e natureza”. Além de que os modelos nem sempre buscam quebrar o vínculo com o capitalismo, mas sim adaptar os modos de vida alternativos a essa realidade.

O mundo não é homogêneo em nenhum aspecto, inclusive na maneira como as diferentes sociedades se relacionam com a natureza. Desse modo, diferentes modelos devem ser aplicados a diferentes sociedades. Entende-se, ademais, que esses modelos devam surgir endogenamente, primeiramente porque melhor se adaptam as formas de vida de dita população humana e, em segundo lugar, porque mais facilmente se aceita algo que surge como uma mudança necessária para o próprio grupo do que uma imposição vertical. Destarte, compreende-se a necessidade de se pensar a partir da perspectiva decolonial, buscando a qualidade de vida, tendo em vista a realidade social, cultural e ambiental do local.

No caso das comunidades indígenas brasileiras, estas ainda estão em condição de tutela e lutam pela autonomia, autogoverno e autogestão de seus territórios, bem como a criação e execução de projetos que sejam consonantes com suas visões de qualidade de vida ou, até mesmo, de "desenvolvimento".

Embora as comunidades indígenas brasileiras estejam buscando amparo na legislação para que desenvolvam seus próprios modos de desenvolvimento, elas ainda estão amarradas ao processo burocrático brasileiro e ao modelo de desenvolvimento sustentável. A regulamentação de algumas atividades em TIs, entre elas o turismo, ao invés de contribuir para a autonomia desses povos, ainda está enraizada na tutela. Além disso, a burocracia para que as comunidades se adéquem à legislação, é um entrave, resultado da cópia de modelos ocidentais-capitalistas-hegemônicos.

\section{REFERÊNCIAS}

Acselrad, H. (2004). As práticas espaciais e o campo dos conflitos ambientais. In: Acselrad, H. (Org.). Conflitos ambientais no Brasil. Rio de janeiro: Relume Dumara/ Fundação Heinrich Böll.

Acselrad, H. (2010). Ambientalização das lutas sociais - o caso do movimento por justiça ambiental. Estudos Avançados, 24(68), 103-119.

Brandão, C. N. (2012). Turismo em Terras Indígenas como fator de desenvolvimento local sustentável: estudo de caso nas comunidades indígenas de Roraima. 158 p. Dissertação de Mestrado, Fundação Getúlio Vargas/SP, São Paulo. Recuperado em 04 de julho, 2016, de 
http://bibliotecadigital.fgv.br/dspace/bitstream/handle/10438/10293/Disserta\%C3\%A7\%C3\% A3o_Mestrado_Final_Version_2012.pdf?sequence=1.

Cavalcanti, C. (2012). Sustentabilidade: mantra ou escolha moral? uma abordagem ecológicoeconômica. Estudos Avançados, 26(74), 35-50. Recuperado em 10 de setembro, 2016, de http://www.scielo.br/pdf/ea/v26n74/a04v26n74.pdf.

Cavalcanti, C. (2015, dez.). Pensamento socioambiental e a economia ecológica: nova perspectiva para pensar a sociedade. Desenvolvimento e Meio Ambiente, 35, 169-178. Recuperado em 11 de setembro, 2016, de http://revistas.ufpr.br/made/article/view/43545/27093.

Constituição Federal. (1988, 5 de outubro). Constituição da República Federativa do Brasil de 1988.

Corbari, S. D., Bahl, M., \& Souza, S. do R. (2016a). Reflexões sobre conceitos e definições atinentes ao turismo envolvendo comunidades indígenas. Revista Investigaciones Turísticas, 12, 50-72. Recuperado em 22 de janeiro, 2017, de https://rua.ua.es/dspace/bitstream/10045/61310/1/Investigaciones_Turisticas_12_03.pdf.

(2016b). A Semana Cultural Indígena da comunidade de Tekohá Ocoy, São Miguel do Iguaçu, Paraná (Brasil) como meio de divulgação e valorização sociocultural. Turismo \& Sociedade, 9(1), p. 1 - 25. Curitiba. Recuperado em 29 de julho, 2017, de

http://revistas.ufpr.br/turismo/article/view/48298/29363.

Decreto n. 5.051 de 19 de abril de 2004 (2004, 20 de abril). Promulga a Convenção $n^{o} 169$ da Organização Internacional do Trabalho - OIT sobre Povos Indígenas e Tribais. Diário Oficial da União, seção 1. Recuperado em 14 de setembro, 2016, de http://www.planalto.gov.br/ccivil_03/_ato2004-2006/2004/decreto/d5051.htm.

Decreto n ${ }^{\text {7 7.747, de }} 5$ de junho de 2012 (2012, 6 de junho). Institui a Política Nacional de Gestão Territorial e Ambiental de Terras Indígenas - PNGATI, e dá outras providências. Diário Oficial da União, seção 1. Recuperado em 15 de setembro, 2016, de http://www.planalto.gov.br/ccivil_03/_ato2011-2014/2012/decreto/d7747.htm.

Diegues, A. C. (1992). Desenvolvimento sustentável ou sociedades sustentáveis: da crítica dos modelos aos novos paradigmas. São Paulo em Perspectiva, 6(1-2), 22-29. Recuperado em 10 de setembro, 2016, de http://produtos.seade.gov.br/produtos/spp/v06n01-02/v06n0102_05.pdf.

Faria, I. F. de. (2008). Ecoturismo indígena - território, sustentabilidade, multiculturalismo: princípios para a autonomia. Tese de Doutorado, Universidade de São Paulo, São Paulo. Recuperado em 27 de julho, 2015, de http://www.teses.usp.br/teses/disponiveis/8/8135/tde17022011-095412/pt-br.php.

Foladori, G. (2001). Limites do desenvolvimento sustentável. São Paulo: Editora da Unicamp/Imprensa Oficial.

Fortunato, R. A., \& Silva, L. S. (2013). Os conflitos em torno do Turismo Comunitário na Prainha do Canto Verde (CE). Revista Brasileira de Ecoturismo, 6(1), 123-138. Recuperado 
em

de

julho,

2015

de

http://www.sbecotur.org.br/rbecotur/seer/index.php/ecoturismo/article/view/481/41.

Furtado, C. (2002). Em busca de novo modelo. São Paulo: Editora Paz e Terra.

Godoy. A. M. G. (s/d). Padrão de desenvolvimento e meio ambiente. Textos para discussão, Programa de Pós-Graduação em Meio Ambiente e Desenvolvimento, Universidade Federal do Paraná.

Guimarães, R. P., \& Fontoura, Y. S. dos R. da. (2012). Rio+20 ou Rio-20? Crônica de um fracasso anunciado. Ambiente e Sociedade, 15(3), 19-39. Recuperado em 10 de setembro, 2016, de http://www.scielo.br/pdf/asoc/v15n3/a03v15n3.pdf.

Instrução Normativa n. 003 de 11 de junho de 2015 (2015, 12 de junho). Estabelece normas e diretrizes relativas às atividades de visitação para fins turísticos em terras indígenas. Diário Oficial da União, seção 1. Recuperado em 04 de agosto, 2015, de http://pesquisa.in.gov.br/imprensa/jsp/visualiza/index.jsp?jornal=1\&pagina $=41 \&$ data $=12 / 06 / 2$ 015 .

Larrea, A. M. (2010). La disputa de sentidos por el buen vivir como processo contrahegemónico. In: Secretaría Nacional de Planificación y Desarrollo (SENPLADES), Instituto de Altos Estudios Nacionales (IAEN), \& Ministerio Coordinador de la Política (MCP). Los nuevos retos de America Latina: socialismo y Sumak Kawsay, 15-28.

\section{SENPLADES: Quito.}

Layrargues, P. P. (1997). Do ecodesenvolvimento ao desenvolvimento sustentável: evolução de um conceito? Proposta, 24(71), 1-5.

Leff, E. (2000). Ecologia, capital e cultura: racionalidade ambiental, democracia participativa e desenvolvimento sustentável. (Trad. Jorge Esteves da Silva). Blumenau: Editora da FURB.

Luciano, G. J. dos S. (2008). Povos indígenas e etnodesenvolvimento no Alto Rio Negro. In: Athias, R., \& Pinto, R. P. (Org.). Estudos indígenas: comparações, interpretações e políticas, 27-44. São Paulo: Contexto. Série Justiça e Desenvolvimento.

Martinez-Alier, J. (2007). O ecologismo dos pobres: conflitos ambientais e linguagens de valoração. (Trad. Mauricio Waldman). São Paulo: Contexto.

Max-Neef, M. (2012). Desenvolvimento à escala humana: concepção, aplicação e reflexões posteriores. (Trad. Rede Viva). Blumenau: Edifurb.

Oliveira, P. C. de. (2008). Gestão territorial indígena: perspectivas e alcances. In: Athias, R., \& Pinto, R. P. (Org.). Estudos indígenas: comparações, interpretações e políticas, 175-192. São Paulo: Contexto. Série Justiça e Desenvolvimento.

Organização das Nações Unidas (ONU). (1987). Our Common Future, Chapter 2: Toward Sustainable Development. Recuperado em 10 de setembro, 2016, de http://www.undocuments.net/ocf-02.htm.

Pierri, N. (1997). El precio del ecosistema global: elementos para su interpretación. Jul. 1999. Comentário crítico do artigo de Constanza, R. d'A., d'Arge, R., Farber, S., Grasso, M., 
Hannon, B; Limburg, K., Naeem, S., O’Neill, R., Paruelo, J., Raskin, G. R., Sutton, P., \& Van den Belt, M. The value of the world's ecosystem services and natural capital. Nature, 387, 253-260.

Pierri, N. (2001). Historia del concepto de desarrollo sustentable. In: Foladori, G., \& Pierri, N. (Eds.) ¿Sustentabilidad? Desacuerdos sobre el desarrollo sustentable, 27-81. Uruguai: Trabajo y Capital.

Pierri, N. (2004). O processo que conduz à proposta hegemônica de desenvolvimento sustentável e as alternativas em discussão. Textos para discussão, Programa de PósGraduação em Meio Ambiente e Desenvolvimento, Universidade Federal do Paraná.

Sachs, I. (2008). Desenvolvimento: includente, sustentável, sustentado. Rio de Janeiro: Garamond.

Sampaio, C. A. C. (2009). Gestão que privilegia uma outra economia: ecossocioeconomia das organizações. Blumenau: FURB.

Azkarraga, E. J., \& Altuna, G. L. A. (2009). Pensando la experiencia de cooperativismo de Mondragón bajo la mirada de la ecosocioeconomía de las organizaciones. Mondragón: Economía Social y Cooperativismo.

Zhouri, A., \& Laschefski, K. (2010). Desenvolvimento e conflitos ambientais. Belo Horizonte: Editora UFMG. 